\title{
A THREE-PHASE POWER-FACTOR CORRECTION SCHEME USING AN AUTOTRANSFORMER AND TWO SINGLE-PHASE BUCK RECTIFIERS
}

\author{
Geovane Duarte Pinheiro, Alceu André Badin, Roger Gules and Eduardo Ribeiro Felix Romaneli \\ Federal University of Technology - Parana - UTFPR \\ Curitiba, PR \\ dgeovane@gmail.com, badin@utfpr.edu.br,rgules@gmail.com and felix@utfpr.edu.br.
}

\begin{abstract}
This paper presents a three-phase unidirectional rectifier with power-factor correction (PFC) using two modified single-phase Buck rectifiers in continuous conduction mode (CCM). The phase reduction technique using an autotransformer based on Scott Connection renders a non-isolated rectifier to operate with unity power factor. The power of autotransformer is only $14 \%$ of the total output power.

Two single-phase buck rectifiers interleaved are able to regulate low voltage output. The control system is simple and it has only one voltage control loop. Theoretical analysis, design procedure and complete simulation results with closed loop operation are given. A 4-kW prototype has also been implemented in the laboratory which demonstrated to operate successfully with excellent performance.
\end{abstract}

Keywords - AC-DC converters, buck rectifier, PFC converters, Scott autotransformer, sinusoidal pulse width modulated.

\section{INTRODUCTION}

Three-phase switch-mode power supplies employing diode-rectifier-type utility interface are widely used in telecommunications, data processing, and other industrial systems. Those converters connected to the mains have the potential of injecting current harmonics that may cause voltage distortion. Due to power quality requirements at input $\mathrm{AC}$ lines, several standards have been developed and are being enforced on the consumers. [1]-[2].

The harmonics can be significantly reduced if the input power factor is corrected by shaping the input current in each of the three phases so that it is sinusoidal and in phase with the phase voltage. Therefore, switch-mode rectifiers for power factor correction (PFC) have gained considerable attention. Further advantages for the use of PFC rectifiers are their adaptability to different line voltages and the fact that they pre-regulate the DC output voltage, which may be supplying a DC-DC converter.

The advances in PFC converter technology have enabled the development of single-phase AC-DC converters. Most of those converters use single-switch DC-DC converter topologies. Also, PFC rectifiers are widely researched techniques, well known and used in products and industries.

A simple way to obtain three-phase rectifier with high power factor is to use three single-phase PFC converters, one

Manuscript received 04/02/2014; revised 14/11/2014; accepted for publication 22/03/2015, by recommendation of the Special Section Editor Mário Lúcio da Silva Martins. per phase. In [3], a three-phase switch-mode rectifier employing three single-phase boost PFC circuits with direct output coupling is presented. Another solution using three single-phase modules associated with an uncontrolled rectifier is presented in [4]. However, these topologies have a high number of components.

In [5] is proposed a three-phase single-switch boost converter that can be designed to operate so that its line currents operate in the discontinuous conduction mode (DCM) and high power factor. However, the output voltage is always higher than input voltage. Also, the Total harmonic distortion (THD) depends on the output power. When the power is less than nominal output power THD is increased and power factor is reduced. In [6] is proposed another converter with buck-boost type. It has the same disadvantages of the proposal [5].

The Scott connection is one alternative to convert the three-phase to two-phase transformation which uses two single-phase transformers, [7]-[12]. The connection is obtained with two single phase transformers.

In [7], an isolated three-phase buck rectifier based on Scott Transformer is presented. The proposed topology uses two single-phase buck rectifiers in continuous conduction mode with output connected in series and in [8], an output connected in parallel is presented. However, in many applications isolation is not required. Also, the low frequency transformers are expensive and increase the cost and volume. When isolation is not required rectifiers not isolated are more competitive.

The two-phase system can be obtained by means of a center-tapped autotransformer according to the scheme shown in Figure 1. In this technique, the output voltages are $90^{\circ}$ phase shifted between them.

In [13] and [14], a three-phase PFC converter is proposed using two single-phase boost rectifier modules (Figure 2). In [14] the two-phase system is produced by means of a Scott autotransformer connected to the three-phase input. In both articles output voltages higher than the input voltage are proposed.

In this paper, a three-phase buck rectifier with a Scott autotransformer is presented, substantiated by a detailed discussion involving theoretical considerations and finally a prototype is designed to prove the proposed performance. The proposed topology is shown in Figure 3.

The three-phase buck rectifier based of the Scott autotransformer has the same advantages of the single phase buck rectifier: regulated output voltage, only one LC output filter, absence of inrush current and protection against short circuit. This can be used in the DC motor speed control, battery charging, regulated DC supply, among others. 


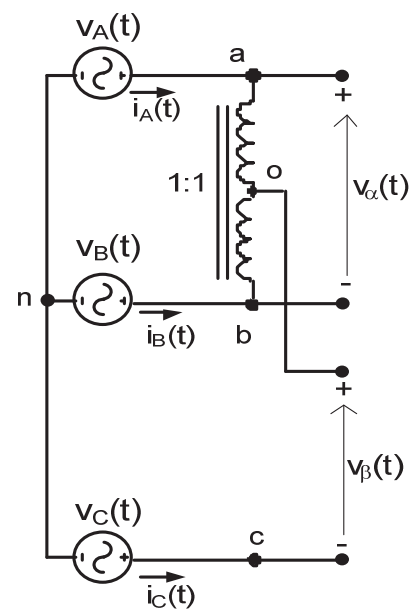

Fig. 1. Scott connection autotransformer.

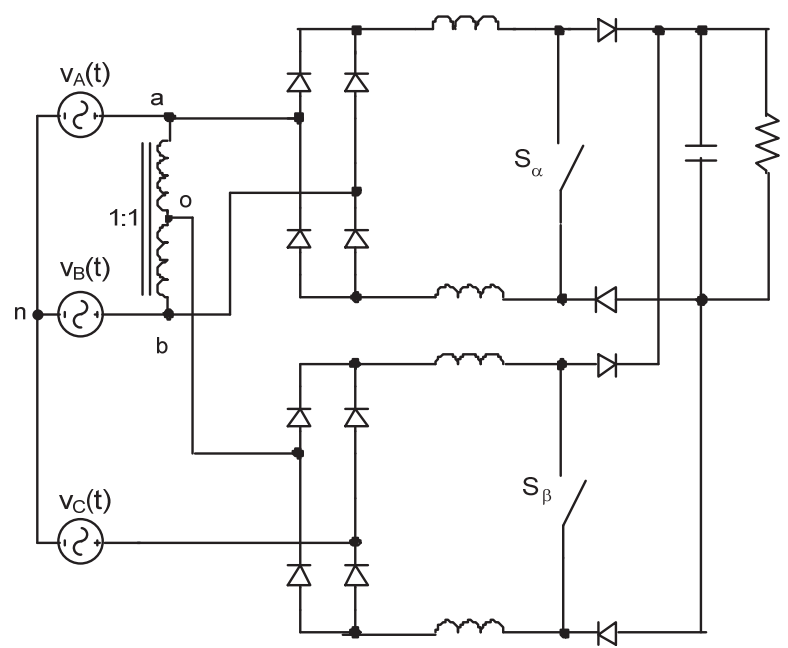

Fig. 2. Unity power factor three-phase boost rectifier with scott autotransformer [7].

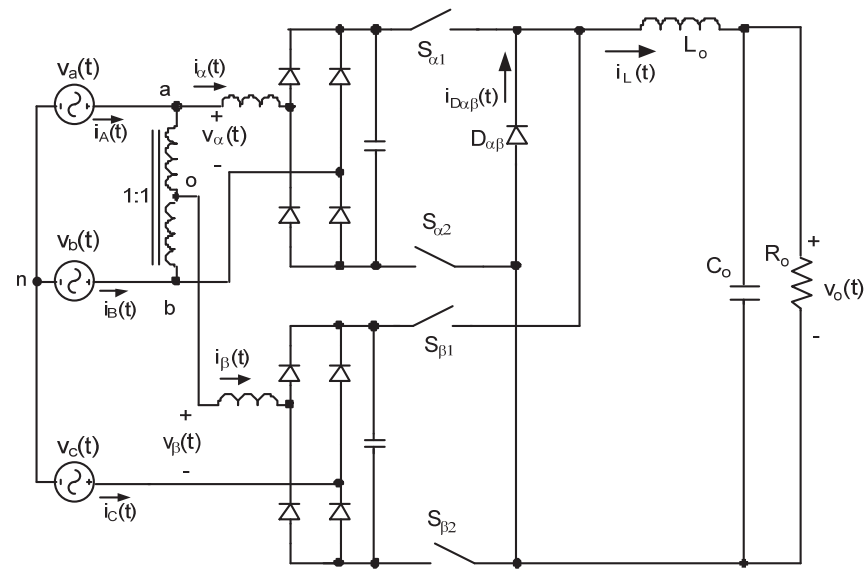

Fig. 3. Unity power factor isolated three-phase buck rectifier with a new series-connection technique.

\section{PROPOSED SYSTEM}

The three phase buck rectifier uses two single-phase buck modules in continuous conduction mode (CCM) and an autotransformer based on Scott Connection for three-phase topology.

\section{A. Single-phase buck rectifier}

The basic circuits of single-phase buck rectifier combines a diode rectifier with a step-down chopper with input and output filters. In the discontinuous conduction mode (DCM), the input current harmonic distortion depends on the ratio between the output voltage average value and the input voltage peak value, which is a downside. Another disadvantage of the DCM is that the peak and RMS currents are very high, leading to pronounced conduction losses in the switches, [15]-[18]. Alternatively, in a CCM, with a low frequency output inductor designed in such a way that it behaves as a constant current source, the problem stated above no longer exists [15]. Albeit, as a drawback, this mode requires much larger inductance than that of DCM. Thus, larger inductance increases physical size, weight and cost of the inductor.

The single-phase buck pre-regulator with feedforward of the output inductor current [18] is shown in Figure 4. This technique proposes to eliminate the distortion of the input current even when the output inductor current presents a large ripple. In this control strategy, the output voltage sample is compared to a reference voltage and the resulting error is injected in an appropriate voltage controller. The output of the controlled voltage is multiplied by a sample of rectified input voltage and divided by a sample of the current in the output inductor. Finally, this resulting signal is compared with the saw-tooth signal thus generating the drive signal to the switch.

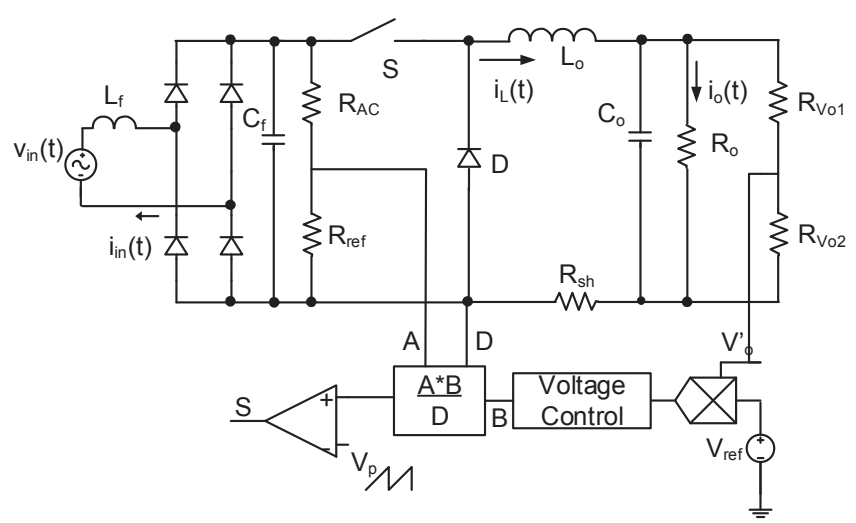

Fig. 4. Single-phase Buck rectifier with feedforward of the output inductor current.

\section{B. The Scott connection autotransformer}

In the Scott connection autotransformer, the primary windings are fed by symmetrical three phase system $v_{A}(t)$, $\mathrm{v}_{\mathrm{B}}(\mathrm{t})$ and $\mathrm{v}_{\mathrm{C}}(\mathrm{t})$. Therefore, the voltages at the inputs are: 


$$
\begin{aligned}
& v_{A}(t)=V_{p} \cdot \sin (\omega t) \\
& v_{B}(t)=V_{p} \cdot \sin \left(\omega t-120^{\circ}\right) \\
& v_{C}(t)=V_{p} \cdot \sin \left(\omega t+120^{\circ}\right)
\end{aligned}
$$

The voltages $v_{\alpha}(t)$ and $v_{\beta}(t)$ represent a two phase voltage system with a phase angle of $90^{\circ}$ between them. The phasor diagram is represented in Figure 5. Therefore, the output voltages are:

$$
\begin{aligned}
& v_{\alpha}(t)=v_{A}(t)-v_{B}(t)=v_{A B}(t) \\
& v_{\beta}(t)=v_{C}(t)-\frac{v_{A B}(t)}{2}-v_{B}(t)
\end{aligned}
$$
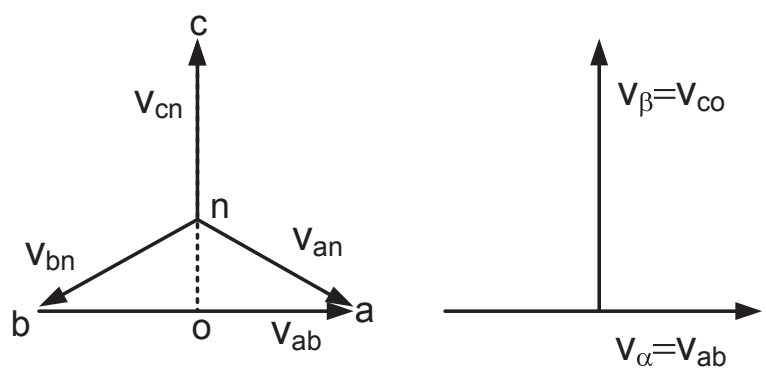

Fig. 5. Phasor diagram of the Scott autotransformer.

Replacing (1) into (2) and (3) yields:

$$
\begin{aligned}
& v_{\alpha}(t)=\sqrt{3} \cdot V_{p} \cdot \sin \left(\omega t+30^{\circ}\right) \\
& v_{\beta}(t)=\frac{3 V_{p}}{2} \cdot \sin \left(\omega t+120^{\circ}\right)
\end{aligned}
$$

The RMS voltage $\left(\mathrm{V}_{\mathrm{AO}}\right)$ and $\mathrm{RMS}$ current $\left(\mathrm{I}_{\mathrm{AO}}\right)$ of each winding of the autotransformer are, respectively:

$$
\begin{gathered}
V_{A O}=\frac{V_{A B}}{2}=\frac{\sqrt{3} V_{p}}{2 \sqrt{2}} \\
I_{A O}=\frac{I_{C}}{2}=\frac{I_{p}}{2 \sqrt{2}}
\end{gathered}
$$

Therefore, the power of the autotransformer is:

$$
P_{A O}=\frac{\sqrt{3} V_{p} I_{p}}{8}
$$

The power of the rectifier is:

$$
P_{o}=\frac{3 V_{p} I_{p}}{2}
$$

The ratio between $\mathrm{P}_{\mathrm{AO}}$ and $\mathrm{P}_{\mathrm{O}}$ is given by:

$$
\frac{P_{A O}}{P_{o}}=\frac{2 \sqrt{3} V_{p} I_{p}}{3 V_{p} I_{p} 8}=\frac{\sqrt{3}}{12} \simeq 0.144
$$

Therefore, the power of the autotransformer is only $14 \%$ of the total output power.

\section{Three-phase buck rectifier proposed}

The circuit states of the converter are shown in Figure 6. The topological state where both switches are turned on is excluded from the operation of the converter.

The mains waveforms of the proposed rectifier are presents in Figure 7. In this scheme, no interactions in the input circuits are considered. The conditions for this to occur must be taken into account in the converter operation.

Due to the fact that the rectifiers are in parallel and $v_{\alpha}(t)$ and $v_{\beta}(t)$ are not isolated, the switches of both rectifier modules must never be turned on simultaneously. Thus, the maximum modulation index is limited. Within this limit it is possible to maintain sinusoidal input currents and, therefore, a unity power factor.

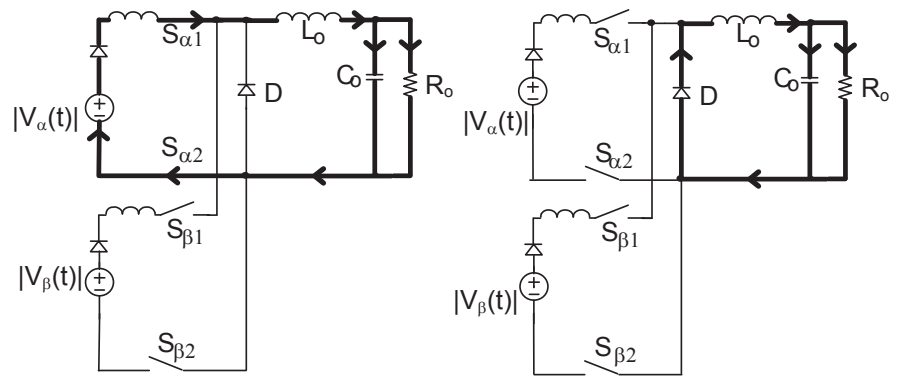

(a)

(b)

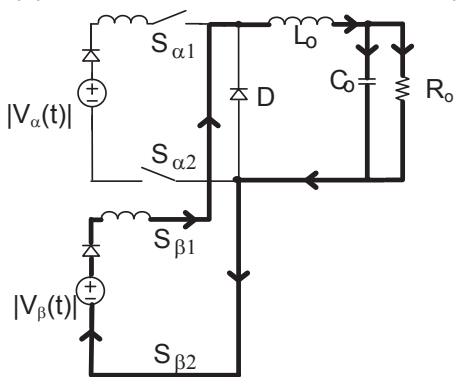

(c)

Fig. 6. States of the circuit: a) $S_{\alpha 1}$ and $S_{\alpha 2}$ on and $S_{\beta 1}$ and $S_{\beta 2}$ off; b) $S_{\alpha 1}, S_{\alpha 2}, S_{\beta 1}$ and $S_{\beta 2}$ off; c) $S_{\alpha 1}$ and $S_{\alpha 2}$ off and $S_{\beta 1}$ and $S_{\beta 2}$ on.

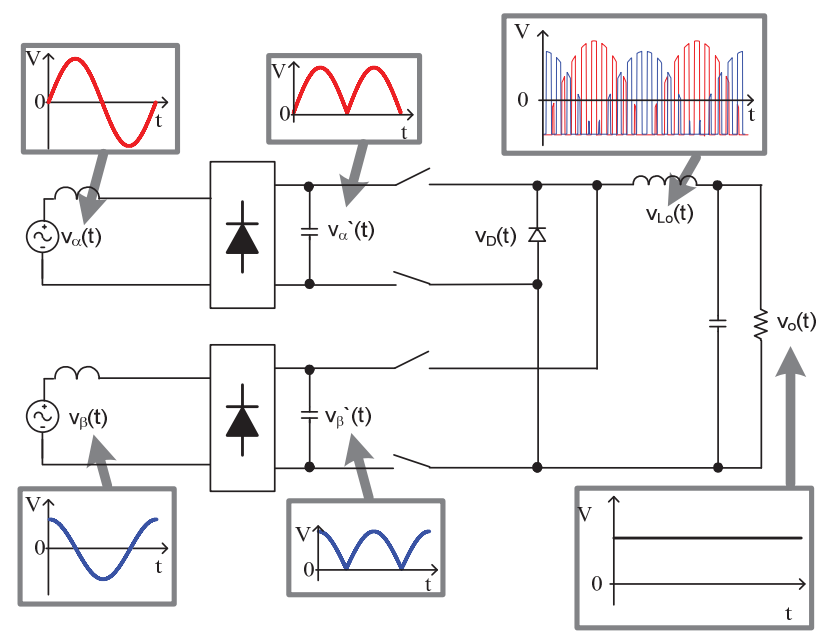

Fig. 7. Mains waveforms of three-phase buck rectifier with Scott autotransformer.

Although voltages $\mathrm{v}_{\alpha}(\mathrm{t})$ and $\mathrm{v}_{\beta}(\mathrm{t})$ are different values, the two buck rectifiers are suitably controlled with different reference currents to supply half of the output power on each single phase converter. Thus, there is a cancellation of the second harmonic component of the inductor current and three-phase input currents are balanced. Therefore, the rectifiers input currents $i_{\alpha}(t)$ and $i_{\beta}(t)$ are: 


$$
\begin{aligned}
i_{\alpha}(t) & =\frac{\sqrt{3} I_{p}}{2} \cdot \sin \left(\omega t+30^{\circ}\right) \\
i_{\beta}(t) & =I_{p} \cdot \sin \left(\omega t+120^{\circ}\right)
\end{aligned}
$$

The purpose of using a buck PFC is to correct the power factor of the structure by forcing the input current to follow the shape of the rectified secondary voltage. For that, instantaneous average duty cycles of the switches are:

$$
\begin{gathered}
d_{\alpha}(t)=\frac{\sqrt{3}}{2} M_{i} \cdot\left|\sin \left(\omega t+30^{\circ}\right)\right| \\
d_{\beta}(t)=M_{i} \cdot\left|\sin \left(\omega t+120^{\circ}\right)\right|
\end{gathered}
$$

Where:

$\mathrm{M}_{\mathrm{i}}$ - Modulation index of buck rectifier connected on $\mathrm{v}_{\beta}(\mathrm{t})$.

In order to reduce the interaction between input phases, duty cycles values is limited. The two single-phase modules can work independently if $180^{\circ}$ phase-shifted PWM carrier signals are used and the duty ratio is limited, so the input interaction is eliminated. Therefore, the amount of $d_{\alpha}(t)$ and $d_{\beta}(t)$ should not be greater than unity in the switching period. Accordingly, the modulation index must be defined by the following equation:

$$
M_{i} \leq \frac{1}{\left|\frac{\sqrt{3}}{2} \sin \left(\omega t+30^{\circ}\right)\right|+\left|\sin \left(\omega t+120^{\circ}\right)\right|}
$$

The maximum value for equation (15) is given by equation (16).

$$
M_{i} \leq \frac{2}{\sqrt{7}} \rightarrow M_{i} \leq 0,756
$$

The limitation of the index modulation allows obtaining sinusoidal input current when there are resistive load and symmetrical voltage inputs. On the other hand, the maximum output voltage is limited by the equation given below:

$$
V_{o}(t) \leq 0,756 \cdot \frac{3}{2} V_{p}=1,134 V_{p}
$$

\section{CONTROL STRATEGY}

Control schemes consist of three control loops: an input voltage feedfoward, an inductor current feedfoward and a feedback output voltage control. Fig. 8 shows the simplified diagram block of control system applied at single-phase buck rectifier.

The modulation signal is obtained by the following equation:

$$
d_{\alpha}=\frac{V_{\alpha}(t) \cdot P I_{V o}}{V_{\alpha R M S}{ }^{2} \cdot I_{L o}(t)}
$$

Where $\mathrm{d}_{\alpha}$ is the modulation signal, $\mathrm{PI}_{\mathrm{Vo}}$ is the output voltage controller and $\mathrm{V}_{\mathrm{aRMS}}$ is the RMS value of the input voltage.

The control strategy has only one output voltage controller and an input voltage feedforward, as typically used in average current mode of the conventional boost PFC. Also, an auxiliary control loop action was developed in order to improve high power factor when the inductor current has a ripple. Thanks this strategy the modulation signal presents a distortion that eliminates the input current distortion due to the output inductor current ripple. In other words, the current feedforward corrects any distortion in the input current caused by the low frequency current ripple in the inductor. Consequently, the inductor current feedforward loop provides a high power factor in this case.

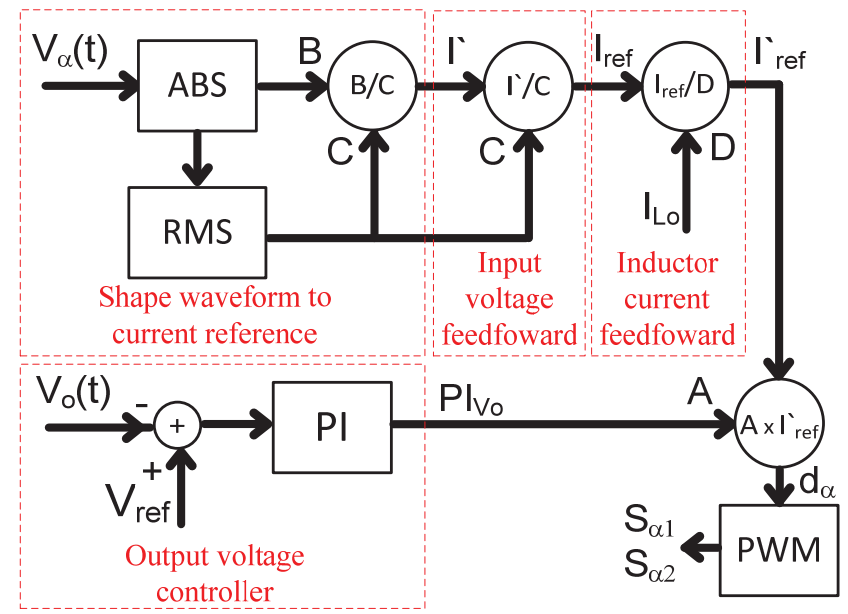

Fig. 8. Simplified control scheme.

Figure 9 shows the control block for the complete system used, where $k_{v}$ is the waveform input gain, $A$ is a voltage error output (PI controller), B is a shape waveform to current reference, $\mathrm{C}$ is a sample of average input voltage and $\mathrm{D}$ is a shape of inductor current ripple. This technique is similar to that in single-phase buck pre-regulator with feedforward of the output inductor current [18]. The division by the inductor current eliminates the distortion of the input current even when the output inductor current presents a large ripple.

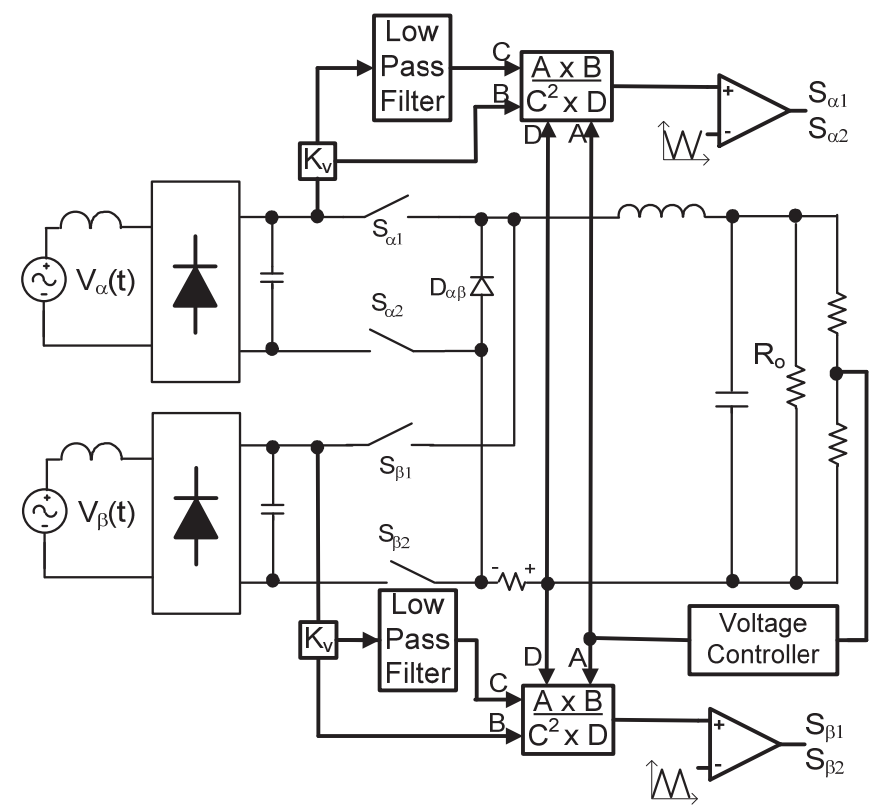

Fig. 9. Complete block diagram of the control loops. 
In an ideal system, line voltages are symmetrical and balanced, therefore, the current feedfoward is not needed because there is no ripple current in the inductor. However, when there are distortions on the line voltages, there are low frequency ripple in the inductor current waveshape. In this case, the current feedforward is needed to provide unity power factor.

Due a line voltages harmonics the output voltage feedback loop have a low-bandwidth in order to avoid distortions in the inputs currents waveform. Therefore, in the output voltage controller is used a PI controller. This type of compensator improves the rejection of disturbances at the frequencies less than crossover frequency in the output voltage.

\section{SIMULATION RESULTS}

In order to analyze the operation of the proposed rectifier, a digital simulation was performed and then compared with experimental results. The proposed control strategy shown in Fig. was implemented, and used for simulation analysis. Table I shows the system specifications.

TABLE I

Circuit parameters and components

\begin{tabular}{cc}
\hline Output power & $4 \mathrm{~kW}$ \\
\hline Output voltage & $220 \mathrm{~V}$ \\
\hline Line frequency & $60 \mathrm{~Hz}$ \\
\hline RMS line voltage & $380 \mathrm{~V}$ \\
\hline Switching frequency & $20 \mathrm{kHz}$ \\
\hline
\end{tabular}

Fig. 10 shows the simulation of lines input currents. The total harmonic distortions of the line currents are lower than $2 \%$.

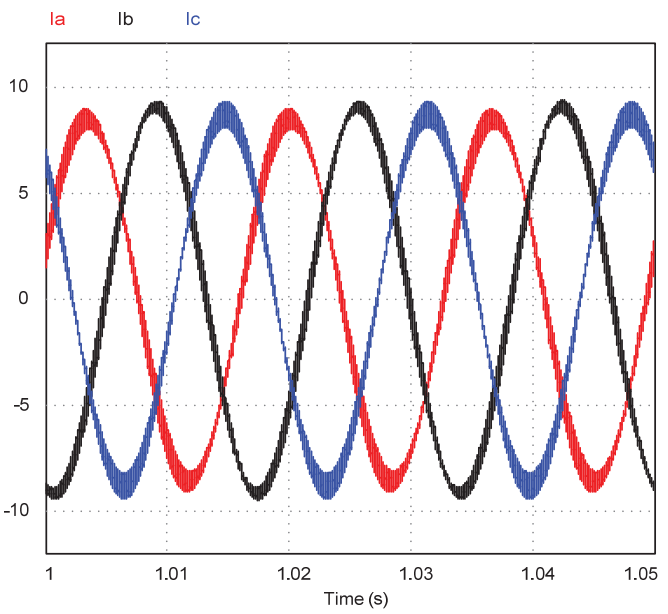

Fig. 10. Input currents $i_{A}(t) i_{B}(t)$ and $i_{C}(t)$.

Fig. 11 shows the simulation of rectifier input currents $\mathrm{i}_{\alpha}(\mathrm{t}), \mathrm{i}_{\beta}(\mathrm{t})$ and the inductor current $\mathrm{i}_{\mathrm{L}}(\mathrm{t})$. The input currents are different value due a input voltages and its presents $90^{\circ}$ phase-shifted from each other. The inductor current has only high frequency ripple.

The power processed in each buck module is shown in Fig. 12. The two PFC modules process the same power.

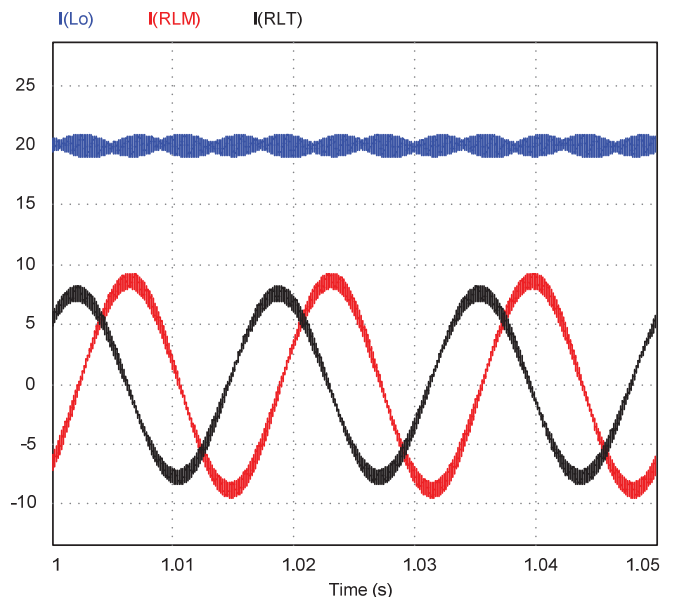

Fig. 11. Inductor current $i_{L}(t)$ and input rectifiers currents $i_{\alpha}(t)$ and $i_{\beta}(t)$.

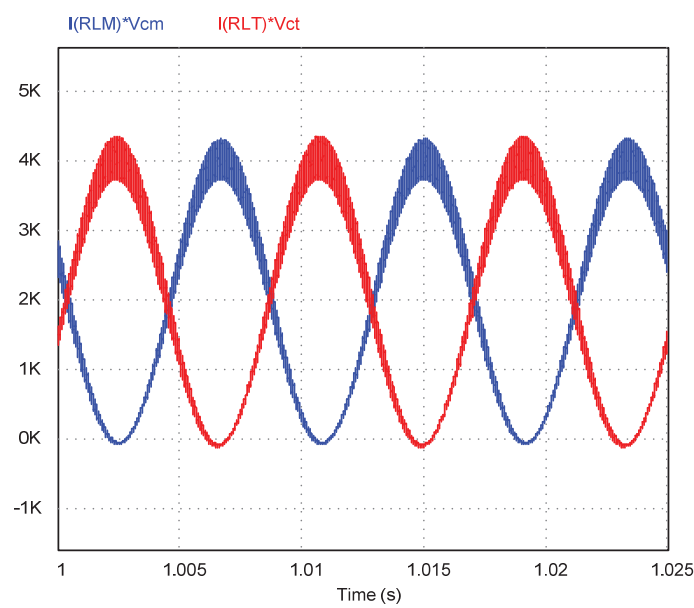

Fig. 12. Power processed at each buck rectifier.

\section{EXPERIMENTAL RESULTS}

A 4-kW three-phase buck non-isolated rectifier prototype was implemented and evaluated in laboratory, in order to validate the proposed structure. The design specifications of the prototype can be seen in Table 1 and Table 2 show the de mains component value. Fig. 13 shows the power circuit implemented

TABLE II

Component value of the rectifier.

\begin{tabular}{ccc}
\hline Circuit element & Nominal Value & Part Number \\
\hline $\begin{array}{c}\mathrm{B}_{\alpha} \text { and } \mathrm{B}_{\beta} \\
\text { (Input bridges rectifiers) }\end{array}$ & $40 \mathrm{~A} / 800 \mathrm{~V}$ & SKKD 40F08 (Semikron) \\
\hline $\mathrm{L}_{\mathrm{o}}$ & $3.5 \mathrm{mH}$ & $\begin{array}{c}\text { laminated iron-core } \\
\text { inductor }\end{array}$ \\
\hline $\mathrm{S}_{\alpha 1}$ and $\mathrm{S}_{\alpha 2}$ & $75 \mathrm{~A} / 1200 \mathrm{~V}$ & SKM 100 GAR 123D \\
(Semikron)
\end{tabular}




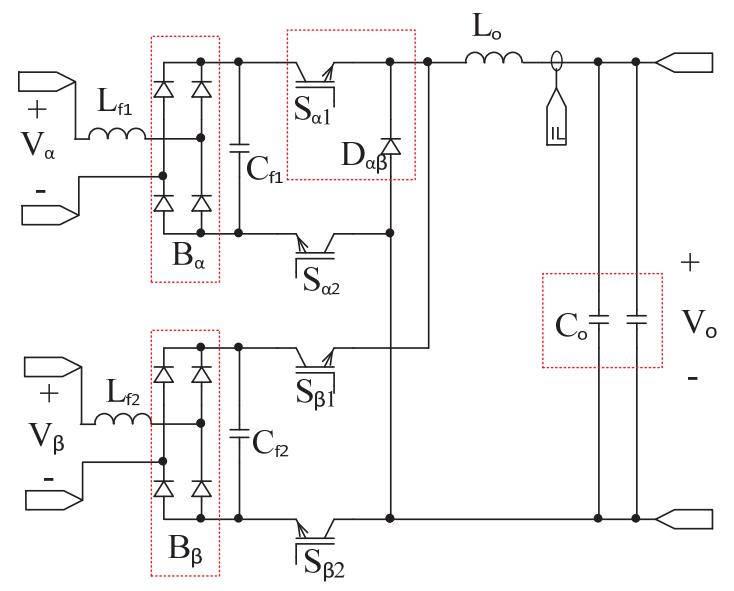

Fig. 13. Implemented prototype: power circuit.

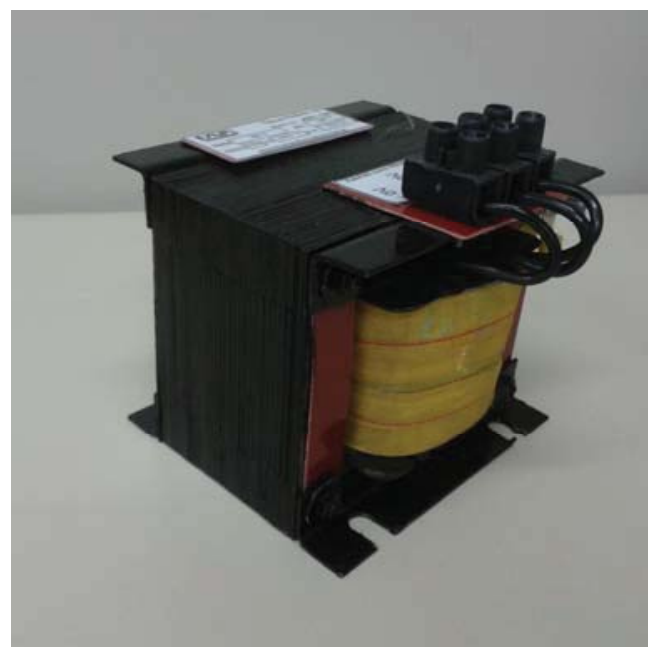

Fig. 14. Photograph of the Scott autotransformer. Dimensions are $115 \mathrm{~mm} \times 70 \mathrm{~mm} \times 94 \mathrm{~mm}$.

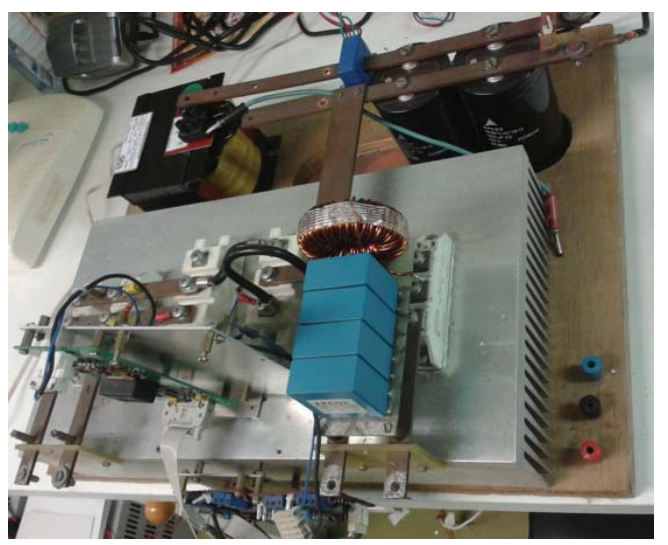

Fig. 15. Photograph of the laboratory prototype.

The experimental line input currents are shown in Figure 9, whereas the total harmonic distortions of the line currents are lower than $4 \%$. They are nearly sinusoidal in shape. The magnitude and shape waveforms are quite different from each other because the input voltages are not symmetrical and have harmonics distortions.

Fig. 17, Fig. 18 and Fig. 19 shows the line currents harmonics magnitudes given as a percentage of the fundamental amplitude. The THD of the line currents were: $2.8 \%, 3.4 \%$ and $3.1 \%$. The power factor per phase was about 0.99 .

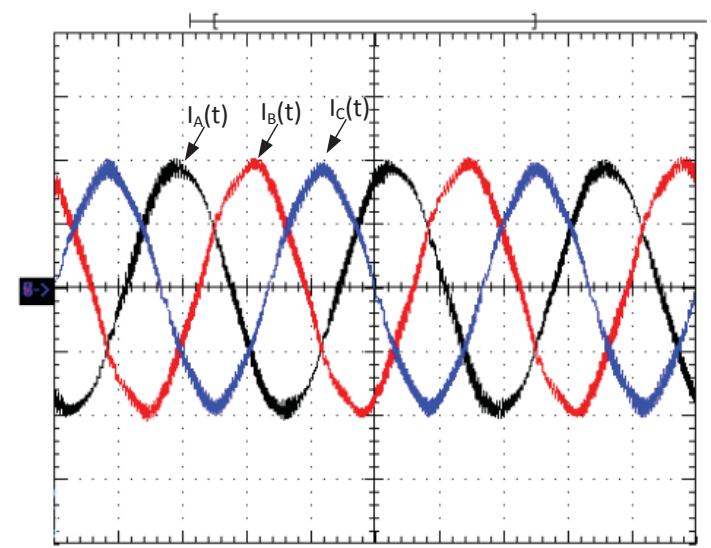

Fig. 16. Input currents $\mathrm{i}_{\mathrm{A}}(\mathrm{t}) \mathrm{i}_{\mathrm{B}}(\mathrm{t})$ and $\mathrm{i}_{\mathrm{C}}(\mathrm{t})(5 \mathrm{~A} /$ division and $5 \mathrm{~ms} /$ division)

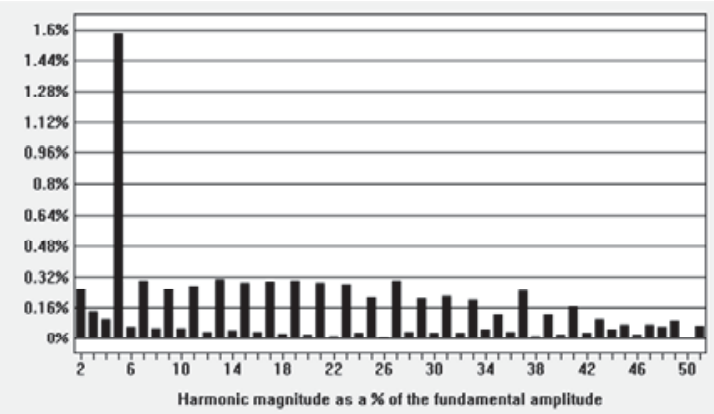

Fig. 17. Normalized line current harmonics $i_{A}(t)$.

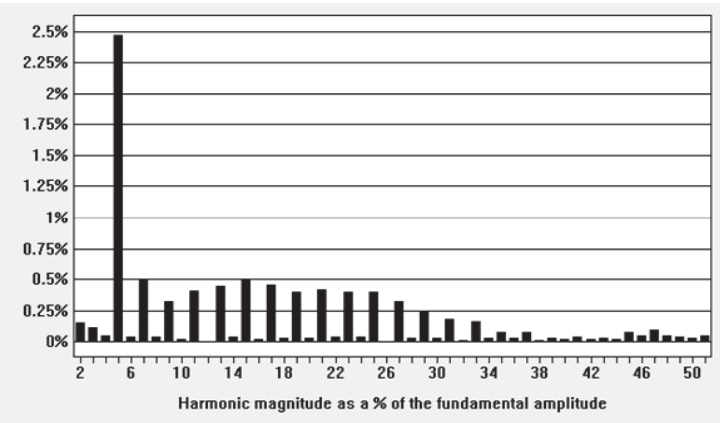

Fig. 18. Normalized line current harmonics $i_{B}(t)$.

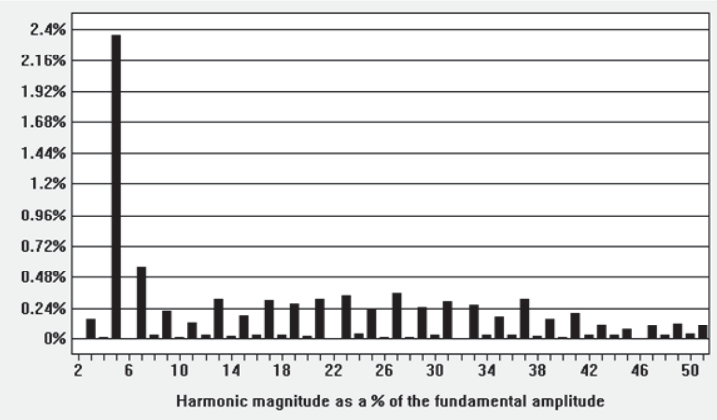

Fig. 19. Normalized line current harmonics $\mathrm{i}_{\mathrm{C}}(\mathrm{t})$. 
Fig. 20 presents the modulation signal with feedforward strategy, which shows a distortion due to the output inductor current ripple.

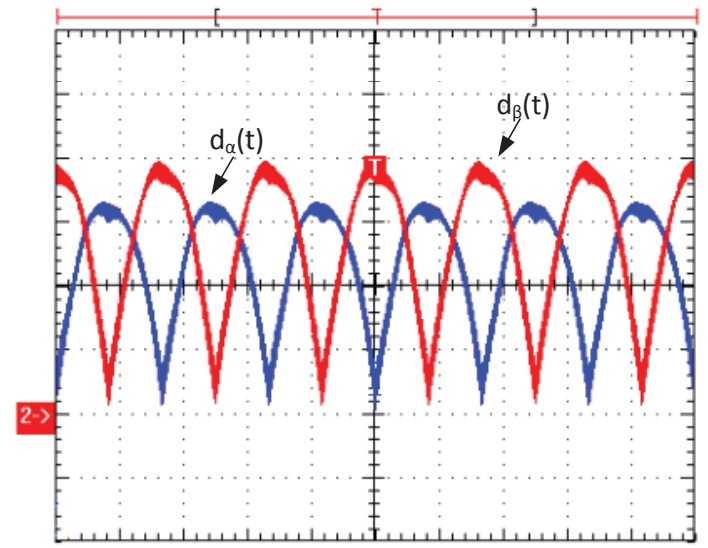

Fig. 20. Modulation signal (1V/division and 10ms/division).

Fig. 21 shows input currents $i_{\alpha}(t)$ and $i_{\beta}(t)$ of the buck PFCs and output inductor current $i_{L}(t)$, where $i_{\alpha}(t)$ and $i_{\beta}(t)$ are $90^{\circ}$ phase-shifted from each other and with different amplitudes.

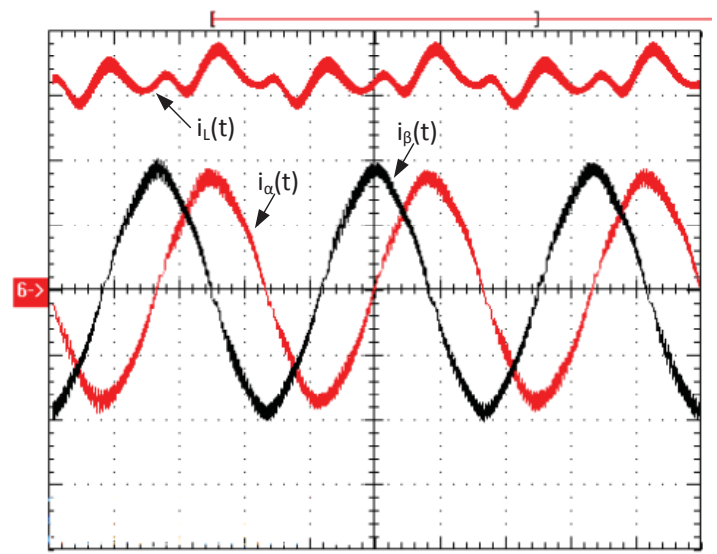

Fig. 21. Inductor current $i_{L}(t)$ and input rectifiers currents $i_{\alpha}(t)$ and $\mathrm{i}_{\beta}(\mathrm{t})(5 \mathrm{~A} /$ division and $5 \mathrm{~ms} /$ division $)$.

The high power factor operation can be observed in Fig. 22 and Fig. 23. The grid voltages present some harmonic distortion and the currents waveform follows the grid voltages waveform as a resistance. The currents and voltages was about $5^{\circ}$ phase-shifted from each other due a input filter.

In Fig. 24 can be seen the output voltage and the rectifier input voltages. The input voltages are different values and represent two phase voltage system with a phase angle of $90^{\circ}$ between them. The output voltage is about $220 \mathrm{~V}$.

The efficiency of the rectifier with autotransformer losses was measured with the digital power meter and the result can be observed in Figure 24. The efficiency data were measured for an output power range $800 \mathrm{~W}$ to $3.9 \mathrm{~kW}$. An efficiency of $94 \%$ was obtained at $3.9 \mathrm{~kW}$, which proves the validity and good performance of the proposed topology. In nominal power the autotransformer losses were approximately $1.2 \%$ of the total output power of rectifier.

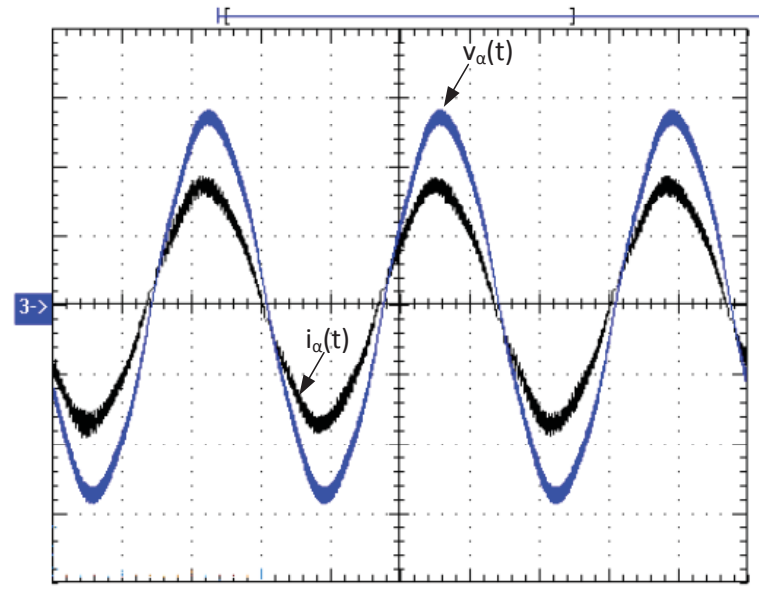

Fig. 22. Input rectifiers voltage $v_{\alpha}(t)$ and currents $i_{\alpha}(t)$ (200V/division, 10A/division and 5ms/division).

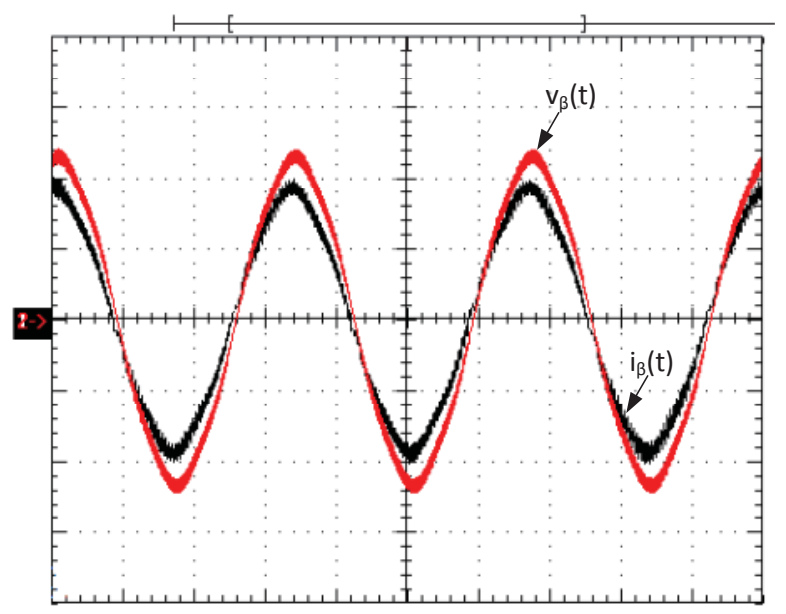

Fig. 23. Input rectifiers voltage $v_{\beta}(t)$ and currents $i_{\beta}(t)$ (200V/division, 10A/division and 5ms/division).

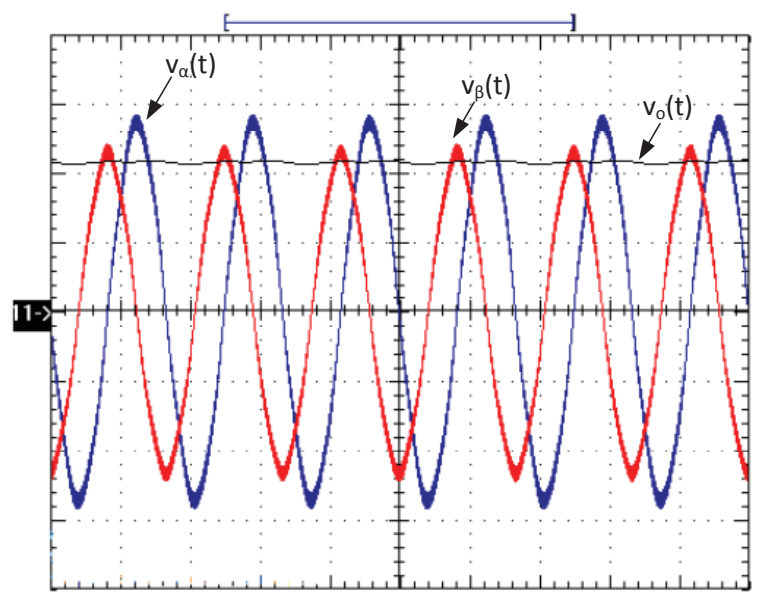

Fig. 24. Input voltages $\mathrm{v}_{\alpha}(\mathrm{t})$ and $\mathrm{v}_{\beta}(\mathrm{t})(200 \mathrm{~V} /$ division and $5 \mathrm{~ms} /$ Division $)$ and output voltage $\mathrm{v}_{\mathrm{o}}(\mathrm{t})(100 \mathrm{~V} /$ division and $10 \mathrm{~ms}$ /division). 


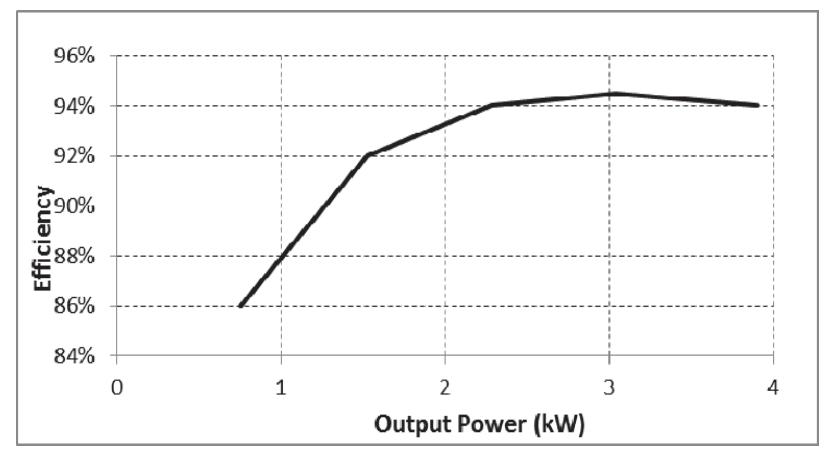

Fig. 25. Prototype efficiency.

The Table III presents comparison of three topologies: buck with autotransformer, buck boost transformer and transformer. Although the number of buck components with autotransformer has a higher number of components, for applications that do not require isolation it has less volume and cost due absence of the transformer.

TABLE III

Rectifiers comparative

\begin{tabular}{cccc}
\hline & $\begin{array}{c}\text { Buck and } \\
\text { autotransformer }\end{array}$ & $\begin{array}{c}\text { Buck and } \\
\text { transformer[7] }\end{array}$ & $\begin{array}{c}\text { Boost and } \\
\text { Transformer[11] }\end{array}$ \\
\hline Isolated & No & Yes & Yes \\
\hline $\begin{array}{c}\text { Power of } \\
\text { transformer }\end{array}$ & $15 \%$ & $100 \%$ & $100 \%$ \\
\hline Switches & 4 & 2 & 2 \\
\hline Diodes & 9 & 9 & 10 \\
\hline Inductors & 3 & 1 & 2 \\
\hline
\end{tabular}

\section{CONCLUSION}

This paper presents a unity power factor three-phase rectifier with only two single-phase buck rectifiers in continuous conduction mode. The phase reduction is achieved by an autotransformer. This topology has only two modules where each buck rectifier is rated for half of the output power. The resulting input line currents are nearly sinusoidal in shape with low harmonic distortion and unity power factor. The power autotransformer is only $14 \%$ of the total output power of rectifier.

The proposed control strategy, which employs a feedforward of output inductor current, allows using high inductor current ripple without distortion input current. Moreover, a small inductor can also be used, which reduces significantly, size, weight and cost of the buck rectifier. A second feedforward input voltage is proposed to distribute the total power between them when the input voltage is unbalanced. Finally, a common voltage control loop for both buck PFCs is employed to regulate the output voltage.

A 4-kW laboratory prototype operating with a switching frequency equal to $20 \mathrm{kHz}$ was implemented. The performance of the proposed converter has been evaluated by the experimental results and obtaining efficiency equal to 94\%. Thus, operates successfully with excellent performance.

\section{ACKNOWLEDGEMENT}

The authors would like to thank the Fundação Araucária, Paraná State Government, CAPES, CNPq, MCT- Ministério da Ciência e Tecnologia and NHS Sistemas de Energia for financial support.

\section{REFERENCES}

[1] IEEE Recommended Practices and Requirements for Harmonics Control in Electric Power Systems, IEEE Std. 519, 1992.

[2] Limits for Harmonic Current Emissions - Equipment Input Current $<16 \mathrm{~A}$ per Phase. IEC 1000/3/2 Int. Std., 1995.

[3] G. Spiazzi and F.C. Lee , "Implementation of singlephase boost power-factor-correction circuits in threephase applications," IEEE Transactions on Industrial Electronics, vol.44, no.3, pp.365-371, 1997.

[4] J.O. Soares, C.A. Canesin, L.C. Freitas and F.A.S. Gonçalves, "Retificador trifasico híbrido operando com controle digital e modulação por histerese." Revista Eletrônica de Potência vol. 13, no4, 2008.

[5] A.R. Prasad, P.D. Ziogas and S. Manias, "An active power factor correction technique for three-phase diode rectifiers," IEEE Transactions on Power Electronics, vol.6, no.1, pp.83-92, 1991.

[6] D.S. Wijeratne and G. Moschopoulos, "A novel threePhase buck-boost AC-DC converter," , IEEE Transactions on Power Electronics, vol.29, no.3, pp.1331-1343, 2014.

[7] A.A. Badin and I. Barbi, "Unity power factor isolated three-phase rectifier with two single-phase buck rectifiers based on the Scott Transformer," IEEE Transactions on Power Electronics, vol.26, no.9, pp.2688-2696, 2011

[8] A.A. Badin and I. Barbi, "High power factor three-phase rectifier with two interleaved single-phase buck rectifier," in Proc. of Power Electronics Conference (COBEP), pp.183,188, 2011.

[9] P. Wolfs, "A Scott transformer based single to three phase power converter for SWER applications," in Proc. of Power Engineering Conference, vol 1. pp.1-6, 2013

[10]V.F. Pires, M. Guerreiro, J.F. Martins and J.F. Silva, "Unity power factor isolated three-phase buck-boost rectifier based on scott transformer," in Proc. of Compatibility and Power Electronics, pp.406-410, 2009.

[11]S.K.T. Miller and I. Barbi, "Practical aspects of the unity power factor isolated three-phase rectifier based on the Scott Transformer," in Proc. of Applied Power Electronics Conference and Exposition, vol.1, pp.621$627,2005$.

[12]G. Bhuvaneswari, B. Singh, and S. Madishetti, "Threephase, two-switch PFC rectifier fed three-level VSI based FOC of induction motor drive," in Proc. of Power India Conference, vol.1, pp.1-6, 2012.

[13]T. Jingtao, L. Yang, Z. Jiang, L. Cai and Y. Jianping, "A Novel Three-Phase Three-Level Power Factor Correction (PFC) Converter Using Two Single-Phase PFC Modules," in Proc. of Power Electronics Specialists Conference, vol.1 pp.3060-3064, 2007

[14]J. Hahn, P.N. Enjeti and I.J. Pitel, "A new three-phase power-factor correction (PFC) scheme using two singlephase PFC modules," IEEE Transactions on Industry Applications, vol.38, no.1, pp.123-130, 2002. 
[15]H. Endo, T. Yamashita and T. Sugiura, "A high-powerfactor buck converter," in Proc. of Power Electronics Specialists Conference, vol.2 pp.1071-1076, 1992.

[16]B. Singh, B. N. Singh, A. Chandra, K. Al-Haddad, A. Pandey and D.P. Kothari, "A review of single-phase improved power quality AC-DC converters," IEEE Transactions on Industry Electronics, vol.50, no.5, pp. 962-981, 2003.

[17]A. Nakajima, S. Motegi and A. Maeda, "Comparison of the characteristics between buck and buck-boost highpower-factor converters with pulse-space-modulation," in Proc. of Industrial Electronics Society, vol.1, pp.168-173, 1999.

[18]F.P. de Souza and I. Barbi, "A unity power factor buck pre-regulator with feedforward of the output inductor current," in Proc. of Applied Power Electronics Conference and Exposition, vol.2, pp.1130-1135, 1999.

[19]P.C. Todd, "UC3854 controlled power factor correction circuit design", Unitrode Corp., Merrimack, NH, Unitrode Application Note U-134, 1999.

[20]10MHz, 4-Quadrant Multiplier/Divider: AD734A, Analog Devices, Inc., Norwood, MA, 1999.

\section{BIOGRAPHIES}

Geovane Pinheiro Duarte received a B.Sc. degree in e automation and control engineering from the College Assis Gurgacz, Cascavel, PR, in December 2007. He is currently working toward the M.Sc degree in electrical engineering from the Federal University of Technology - Paraná, Brazil. Since 2010, he has been professor at the College Assis Gurgacz. His research interests are rectifiers with high power factor and power factor correction.

Alceu André Badin was born in Maravilha, Santa Catarina, Brazil, in 1979.
He received the B.Sc., M.Sc. and Ph.D. degrees in electrical engineering from the Federal University of Santa Catarina, Florianopolis, Brazil, in 2002, 2004, and 2009, respectively.

Since 2010, he has been a Professor at the Federal University of Technology - Paraná, Brazil. His current research interests include high-frequency power converter topologies, power factor correction techniques and power supplies.

Prof. Badin is a member of the Brazilian Power Electronics Society (SOBRAEP) and IEEE Power Electronics Society.

Eduardo Felix Ribeiro Romaneli received a B.E. (Electrical Engineering) degree from the Federal University of Santa Catarina, Brazil, in January 1993; Master and Doctorate degrees in Electrical Engineering also from the Federal University of Santa Catarina in March 1998 and December 2001, respectively. Since 2003, he has been fulltime professor at Federal University of Technology Paraná, Brazil. His research has spanned several disciplines, emphasizing power electronics. His interests are focused, but not restricted, to UPS, power factor correction and digital control.

Roger Gules was born in Bento Gonçalves, Rio Grande do Sul, Brazil, in 1971. He received the B.S. degree from the Federal University of Santa Maria, Rio Grande do Sul, and the M.S. and Ph.D. degrees from the Federal University of Santa Catarina, Florianopolis, Brazil, in 1998 and 2001, respectively.

From 2001 to 2005, he was a Professor at the Universidade do Vale do Rio dos Sinos, Rio Grande do Sul. Since 2006, he has been a Professor at the Federal University of Technology - Paraná, Curitiba,'Brazil. His current research interests include power-switching converters and renewable energy applications. 